\title{
Protective effect of alpha lipoic acid on diabetic nephropathy in rats
}

\author{
Samar Yabes ${ }^{1}$, Mohamed EL-Adl ${ }^{1}$, Mohamed Hamed ${ }^{2}$, Gehad El-Sayed ${ }^{1}$ \\ ${ }^{1}$ Department of Biochemistry and Chemistry of Nutrition, Faculty of Veterinary Medicine, Mansoura University, P.O. 35516, Mansoura, Egypt. \\ ${ }^{2}$ Department of Pathology, Faculty of Veterinary Medicine, Mansoura University, P.O. 35516, Mansoura, Egypt.
}

\section{ARTICLE HISTORY}

Received: 23.07.2019

Revised: 19.08 .2019

Accepted: 23.08.2019

Address correspondence to Mohamed ElAdl; Tel: 01116209784; Email:

drmohamedalymaher@hotmail.com

\section{ABSTRACT}

\begin{abstract}
Objective: To evaluate the protective role of alpha lipoic acid in rats affected with experimentally-induced diabetes and secondarily complicated with nephropathy.

Design: Randomized controlled study.

Animals: Forty-eight Sprague Dawley rats.

Procedures: Rats were allocated randomly into four groups (12 each); Control rats (Group 1); alpha lipoic acid (ALA) supplemented rats (Group 2); rats with induced diabetic nephropathy (Group 3), and rats with diabetic nephropathy and supplemented with alpha lipoic acid (Group 4). After one month of experimental induction, serum, plasma and renal tissue samples were harvested to determine glycemic status, renal damage markers, antioxidant status, oxidative and nitrosative stress markers, apoptotic marker and histopathology of kidney tissues.

Results: In comparison with non-supplemented diabetic rats, alpha lipoic acid reduced renal malondialdehyde $(5.74 \pm 0.26$ vs $11.3 \pm 1.96 \mathrm{nmol} / \mathrm{g}$. tissue) and renal nitric oxide (30.06 \pm 2.07 vs $36.6 \pm 1.07 \mathrm{nmol} / \mathrm{g}$. tissue). ALA significantly improved the antioxidant enzyme activity (catalase and reduced glutathione), glycemic status, and decreased caspase 3 concentration $(\mathrm{P}<0.05)$.

Conclusion and clinical relevance: Alpha lipoic acid may be an alternative intervention to alleviate nephropathy as a complication of diabetes. Further studies need to be done in naturally occurring cases.
\end{abstract}

Keywords: Streptozotocin, Diabetic nephropathy, Caspase 3, Alpha lipoic acid.

\section{INTRODUCTION}

Diabetic nephropathy is a serious complication which most frequently occurs in diabetic patients as a result of microvascular lesions in glomerulus of the kidneys. Hyperglycemia increases vascular permeability to glomerulus, and intracapillary pressure which decreases the production of nitric oxide on efferent arterioles with subsequent increase in sensitivity to angiotensin II with endothelial dysfunction. The increase in intracapillary pressure would significantly increase albumin excretion rate that would become irreversible with the lack of control in glycemic status [1].

Alpha lipoic acid (ALA) or thiotic acid is synthesized in hepatic tissues mainly and to certain limits in other organs. ALA is considered as a potent antioxidant which contributes efficiently to various enzymatic actions in mitochondria such as oxidative decarboxylation of alpha keto acids. Moreover, ALA can contribute to modulating the expression of several inflammatory pathways in the body [2]. ALA can be used in treatment of several diseases as an efficient therapeutic agent such as diabetes mellitus [3], cancers [4] and cardiovascular disorders [5]. The mechanism that ALA adopted as a therapeutic agent is through improving the glycemic status, regulating glucoseinsulin relationship, decreasing the incidence of chronic inflammation and maintaining endothelial functions [6]. Moreover, the beneficial effect of ALA in diabetes mellitus is via inducing anti-inflammatory effect, inhibiting effect on nuclear factor kappa beta activity and activating the Mitogen-activated protein kinase/ extracellular signal- regulated kinase (MAPK/ERK) pathway. The protective role of ALA is also extended to its dyslipidemic role that controls the enzyme system responsible for lipid metabolism such as Hydroxy methyl glutrayl CoA (HMG-CoA) reductase [7]. Therefore, the current study was conducted to evaluate the potential protective effect of alpha lipoic acid on diabetic rats exposed to diabetic nephropathy through assessment of oxidant/antioxidant status, apoptotic factor and histopathological alterations.

\section{MATERIALS AND METHODS}

\subsection{Animals}

A total of 48 Sprague Dawley rats were used in the current experiment. They were allocated equally in duplicate in metal cages, where each cage contained six rats for each group. They were supplied daily with clean source of water. Also, clean bedding of sawdust was provided to the cages and was changed twice/week. Animals were left for acclimatization for ten days prior to the induction of the experiment. 
One gram of Streptozotocin (STZ, Sigma Aldrich co., UK), and a capsule of $600 \mathrm{mg}$ of thiotacid (Egyptian International Pharmaceutical Industries Company, Egypt) were used.

\subsection{Experimental design}

After acclimatization, rats were divided into four equal groups in duplicates, where the first group was assigned as a control group (Group 1) that was fed on a commercial diet [8] contained yellow corn, soybean meal, wheat gluten and bran with mineral vitamin and amino acids supplementation. For the second group (Group 2), rats were fed on ALA at a dose of $20 \mathrm{mg} / \mathrm{kg}$ diet [9]. The third group (Group 3) was subjected to type 2 diabetes mellitus by intraperitoneal injection of a single dose of STZ at a dose of $35 \mathrm{mg} / \mathrm{kg}$ body weight, that was solubilized in citrate buffer $(\mathrm{pH} \mathrm{4)}$ [10], and these animals were maintained on the commercial diet. Blood glucose was checked after 96 hours of injection using glucometer (Acc-check), where rats with glucose concentration over $230 \mathrm{mg} / \mathrm{dl}$ were enrolled to accomplish the experiment. The weight of animals was recorded weekly. The last group (Group 4) was subjected to STZ regimen with supplementation of ALA-enriched diet.

\subsection{Collection of blood samples}

After 30 days of experimental induction, rats were anaesthetized with sodium thiopental $(20 \mathrm{mg} / \mathrm{kg}$ b.wt) [11]. After rats were completely sedated, blood was drawn from the heart through cardiac puncture and was collected in a dry, clean, sterile and capped tube that was left to clot, where clear serum sample was aspirated and transferred to clean Eppendorf for estimating serum creatinine [12], urea [13] and insulin [14]. Other portion of the collected blood was transferred to another clean test tube containing sodium fluoride for determination of plasma glucose concentration [13].

\subsection{Animal dissection}

After the blood collection, rats were dissected and kidney was removed, washed by normal saline and divided into three parts. The first part was immersed in $10 \%$ neutral buffered formalin for histopathological examination [15]. The second part was homogenized in phosphate buffer saline $(\mathrm{pH}$ 7.4) for determination of renal reduced glutathione (GSH) concentration [16], renal catalase (CAT) activity [17], renal malondialdehyde (MDA) concentration [18], and renal nitric oxide (NO) concentration [19]. The third part of renal tissues was used to determine caspase 3 concentration using flowcytometry technique [20].

\subsection{Statistical analysis}

Results were expressed as means \pm standard errors of mean, where ANOVA with LSD post hoc multiple comparison test were employed to compare between means. At $p<0.05$, results were considered significant. All statistical tests were conducted using SPSS v.20 [21]

\section{RESULTS}

In Table 1, glucose, insulin and renal damage markers were tabulated. A significant increase in plasma glucose level was shown by group 3, nevertheless was significantly lowered after supplementation of ALA. Serum insulin in group 3 showed the same magnitude as compared to the control group. However, in both group 2 and 4, a marked increase in serum insulin was found ( $P$ $<0.05$ ). In group 3 , the concentration of creatinine showed a significant elevation compared to the other groups $(P<0.05)$, but a significant decrease was observed after supplementation of ALA in group 4 . The levels of serum urea were significantly increased in STZexposed groups, but were also significantly reduced after supplementation of ALA. Moreover, in group 2, a significant decline in urea concentration was observed compared to the control group ( $P$ $<0.05)$.

In Table 2, antioxidant status, oxidative and nitrosative stress markers were presented. Reduced glutathione concentration displayed the highest magnitude in group 2 and group 4, while STZexposed group showed a significant decrease in GSH in comparison with group 2 and 3 . Group 3 had the lowest activity of catalase that was significantly lowered than other studied groups; meanwhile, catalase activity was the highest in group 2 . The levels of lipid peroxidation and nitric oxide were the highest in STZ-exposed group which turned to basal level when ALA was supplemented.

In Figure 1, there was a significant increase in caspase 3 concentrations in rats in group 3 , but these concentrations were lowered significantly by 3 folds in group 4 when ALA was supplemented. Lipoic acid showed a significant increase in caspase 3 in comparison with group 1.

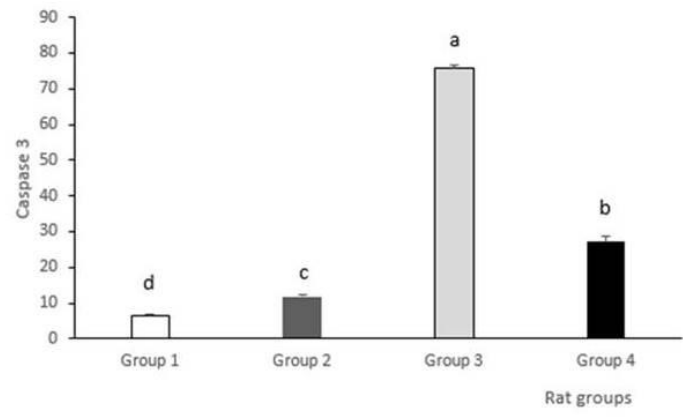

Figure 1. Caspase 3 concentrations in rats exposed to experimental diabetic nephropathy and supplemented with ALA. Bars with different letters indicate significant difference at $P$ $<0.05$. Group 1, control; Group 2, ALA supplemented rats; Group 3, diabetic rats and Group 4, diabetic rats supplemented with ALA.

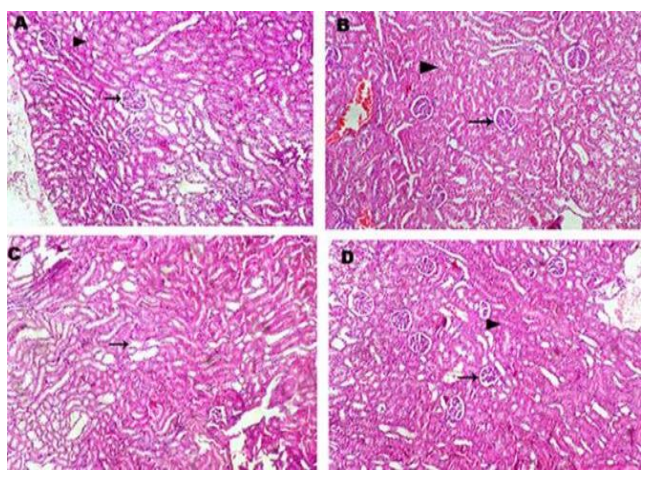

Figure 2. Histopathological findings of kidney in rats exposed to type 2 diabetes mellitus and supplemented with ALA (HE, 100x). Only, kidney of group 3 shows proliferation of renal glomeruli (arrow) with necrosis in renal tubular epithelium (C). However, kidneys of other groups (A, B and D) show normal glomeruli (arrow) with normal renal tubular epithelium (arrow head). 
Histopathological findings were presented in Figure 2. Figure $2 \mathrm{~A}$ showed renal tissues of Group 1 with normal glomeruli (arrow) and renal tubular epithelium (arrow head). In Figure 2B, group 2 revealed also normal glomeruli (arrow) and normal tubular epithelium (arrow head). In Figure $2 \mathrm{C}$, group 3 revealed proliferations in renal glomeruli (arrow) with necrosis in renal tubular epithelium. In figure 2D, group 4 showed normal glomeruli (arrow) with normal renal tubular epithelium (arrow head).

Table 1. Levels of serum glucose, insulin, creatinine and urea (mean $\pm \mathrm{SE}$ ) in rats exposed to experimental diabetic nephropathy and supplemented with ALA.

$\begin{array}{lllll}\text { Group } & \text { Glucose }(\mathrm{mmol} / \mathrm{l}) & \text { Insulin }(\mathrm{ng} / \mathrm{ml}) & \text { Creatinine }(\mathrm{mmol} / \mathrm{l}) & \text { Urea (mmol/I) } \\ \text { Group 1 } & 7.08 \pm 0.087^{b} & 1.98 \pm 0.17^{b} & 0.038 \pm 0.01^{b} & 10.39 \pm 0.19^{b} \\ \text { Group 2 } & 5.55 \pm 0.11^{b} & 6.59 \pm 1.12^{\mathrm{a}} & 0.033 \pm 0.01^{b} & 9.59 \pm 0.12^{c} \\ \text { Group 3 } & 15.04 \pm 1.14^{a} & 1.64 \pm 0.09^{b} & 0.065 \pm 0.004^{a} & 11.49 \pm 0.19^{a} \\ \text { Group 4 } & 7.22 \pm 0.17^{b} & 5.66 \pm 0.62^{a} & 0.036 \pm 0.01^{b} & 8.82 \pm 1.22^{d}\end{array}$

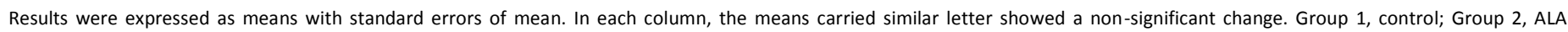
supplemented rats; Group 3, diabetic rats and Group 4, diabetic rats supplemented with ALA.

Table 2. Antioxidant status, oxidative and nitrosative stress markers (mean $\pm \mathrm{SE}$ ) in rats with experimental diabetic nephropathy and supplemented with ALA.

$\begin{array}{llllr}\text { Group } & \text { Renal reduced glutathione concentration } & \begin{array}{l}\text { Renal catalase activity } \\ \text { (mg/g. tissue) }\end{array} & \begin{array}{l}\text { Renal malondialdehyde concentration } \\ \text { (U/g. tissue) }\end{array} & \begin{array}{l}\text { Renal nitric oxide concentration } \\ \text { (nmol/g. tissue) }\end{array} \\ \text { Group 1 } & 2 \pm 0.22^{\mathrm{b}} & 0.95 \pm 0.08^{\mathrm{ab}} & 5.98 \pm 0.25^{\mathrm{b}} & 28.86 \pm 0.66 \mathrm{~b} \\ \text { Group 2 } & 7.46 \pm 0.43^{\mathrm{a}} & 0.97 \pm 0.002^{\mathrm{a}} & 4.99 \pm 0.46^{\mathrm{b}} & 18.69 \pm 1.69 \mathrm{c} \\ \text { Group 3 } & 0.98 \pm 0.1^{\mathrm{b}} & 0.81 \pm 0.02^{\mathrm{c}} & 11.3 \pm 1.96^{\mathrm{a}} & 36.6 \pm 1.07 \mathrm{a} \\ \text { Group 4 } & 8.42 \pm 0.14^{\mathrm{a}} & 0.92 \pm 0.01^{\mathrm{b}} & 5.74 \pm 0.26^{\mathrm{b}} & 30.06 \pm 2.07 \mathrm{~b}\end{array}$

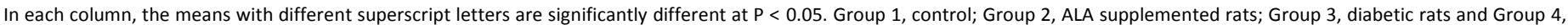
diabetic rats supplemented with ALA.

\section{DISCUSSION}

Diabetes mellitus can lead to end-stage renal diseases and renal failure due to the initiation of diabetic nephropathy and the presence of proteinuria. The progression of diabetic kidney disease could result in a decrease in glomerular filtration rate and loss of kidney molecular structure with thickening in basement membrane and mesangial sclerosis [22].

ALA is a potent antioxidant and is involved in several metabolic processes of glucose oxidation and ATP generation [23], therefore the protective role of ALA in diabetic nephropathy may act through this mechanism.

The concentration of glucose significantly declined in rats exposed to STZ and supplemented with ALA when compared to STZ group which can be attributed to the role of ALA in carbohydrate metabolism and the presence of sulphydryl group that takes part in metabolism of glucose in the body [24]. It can also be recorded that
ALA can increase the sensitivity of peripheral tissues to insulin in type 2 diabetic patients [25] and stimulate tyrosine kinase activity [26]. Moreover, the decline in insulin concentration in rats with induced diabetes was attributed to the damaging effect of STZ on pancreatic cells-secreting insulin. In the current study, the use of the given dose of STZ to develop type 2 diabetes mellitus in rats was discussed because of the fact that chronic treatment with ALA can enhance insulin sensitivity in adipocytes and muscle cells and activate insulin signaling pathways $[27,28]$.

As a complication of diabetic nephropathy, a significant elevation in serum creatinine was observed which was also found in a similar study in diabetic rats exposed to STZ treatment [29]. ALA has the potency to decrease the concentration of creatinine and improve renal filtration rate in the current study which was also observed in similar studies conducted by $[23,30]$. In a similar manner, the concentration of urea was significantly decreased after ALA supplementation in STZ-exposed rats which was also discussed in 
cisplatin-induced kidney damage, where ALA supplementation produced a protective effect and reduced urea concentration in exposed rats [31].

Regarding antioxidant status, a reduction in GSH concentration was observed in diabetic induced rats which is a marked evidence of oxidative stress [32]. Moreover, the oxidative damage produced by diabetes led to the production of superoxide radicals that cause oxidative insults to the renal tissue and is magnified as a result of diabetic nephropathy [33]. The protective effect of ALA on renal tissues is attributed to the antioxidant effect of lipoic acid in preventing the reduction of podocyte density which is a major complication of diabetic nephropathy [34]. In addition, the activity of catalase was significantly decreased in rats exposed to STZ which was also attributed to oxidative stress. ALA was capable of alleviating the oxidative burden on renal tissues because it contains thiols group that act as a potent antioxidant and scavenge free radicals which enhances the host defenses and restores its antioxidant ability [30]. The increase of the amount of lipid peroxidation is a consequence of oxidative stress which was found as a result of diabetes induction in rats.

The marked elevation of lipid peroxidation in the current study could be attributed to low levels of GSH and poor antioxidant capacity of host tissues [35]. ALA can improve antioxidant status of host tissues through decreasing lipid peroxidation [36, 37]. Reactive nitrogen species is produced as a result of the interaction between $\mathrm{NO}$ and superoxide anion which has an immunogenic function in physiological limits, but in higher concentration it might contribute to the pathogenesis of many diseases [38]. There is a marked elevation of nitric oxide concentration as a result of oxidative stress in STZexposed rats, which was significantly decreased after supplementation of ALA to reach to basal levels. A similar study was also carried out by Cho et al., [39]. ALA is found to reduce the release of nitric oxide from macrophages and reduce the attack of reactive oxygen species to the pancreatic Beta cells [40]. Generally, the antioxidant role of ALA is related to its ability to modulate redox potential intracellularly and extracellularly [41].

Caspase 3 concentration showed a significant increase in STZexposed rats which could be due to the necrosis in renal tubular epithelium with the marked proliferation detected in the histopathological examination. It is recorded that patients suffered from diabetes mellitus with chronic periodontitis showed a significant increase in caspase 3 concentration, where a positive correlation was observed between the current glycemic status and the increase in caspase 3 concentration [42]. ALA is capable to suppress apoptosis and decrease the expression of caspase 3 in hippocampal damage which is attributed to its neuroprotective role [43].

\section{Conclusion}

It can be concluded that ALA can be used efficiently in rats suffer from nephropathy as a complication of diabetes mellitus to improve glycemic status, antioxidant defense system and to inhibit apoptosis by reduction of caspase 3 expressions.

\section{Conflict of interest statement}

The authors declare that there is no any conflict of interest in the current research work.

\section{Animal ethics committee permission}

The current research work was conducted according to standards of Research Ethics Committee, Faculty of Veterinary Medicine, Mansoura University.

\section{Author contributions}

S. Y. conducted the experiment and analytical procedures; M. E. performed sample collection, statistical analysis, drafted and submitted the manuscript; $\mathrm{M}$. H. conducted the histopathological examination; G.R. revised the manuscript.

\section{REFERENCES}

[1] Nathan DM, Group DER. The diabetes control and complications trial/epidemiology of diabetes interventions and complications study at 30 years: overview. Diab Care 2014;37:9-16

[2] Gorąca A, Huk-Kolega H, Piechota A, Kleniewska P, Ciejka E, Skibska B. Lipoic acid-biological activity and therapeutic potential. Pharmacol Rep 2011;63:849-58.

[3] Laher I. Diabetes and alpha lipoic acid. Front Pharmacol 2011;2:69.

[4] Feuerecker B, Pirsig S, Seidl C, Aichler M, Feuchtinger A, Bruchelt G, et al. Lipoic acid inhibits cell proliferation of tumor cells in vitro and in vivo. Can biol Ther 2012;13:1425-35.

[5] Wollin SD, Jones PJ. $\alpha$-Lipoic acid and cardiovascular disease. J Nutrit 2003;133:3327-30.

[6] Castro JP, El-Atat FA, McFarlane SI, Aneja A, Sowers JR. Cardiometabolic syndrome: pathophysiology and treatment. Curr Hyperten Rep 2003;5:393-401.

[7] Sena C, Nunes E, Louro T, Proença T, Fernandes R, Boarder M, et al. Effects of $\alpha$-lipoic acid on endothelial function in aged diabetic and high-fat fed rats. Brit J Pharamcol 2008;153:894-906.

[8] NRC NRC. Nutrient requirements of laboratory animals: 1995. Washington, DC.: National Academies Press; 1995.

[9] Ying Z, Kherada N, Farrar B, Kampfrath T, Chung Y, Simonetti O, et al. Lipoic acid effects on established atherosclerosis. Life Sci 2010;86:95-102.

[10] Aybar MJ, Riera ANS, Grau A, Sanchez SS. Hypoglycemic effect of the water extract of Smallantus sonchifolius (yacon) leaves in normal and diabetic rats. J Ethnopharmacol 2001;74:125-32.

[11] Gustafsson LL, Ebling WF, Osaki E, Stanski DR. Quantitation of depth of thiopental anesthesia in the rat. Anesthesiology 1996;84:415-27.

[12] Young D. Effects of drugs on Clinical Lab. Tests, 4th ed AACC Press; 1995

[13] Tietz NW. Clinical guide to laboratory tests. 3rd ed. Philadelphia: WB Saunders Co; USA 1995.

[14] Chevenne D, Letailleur A, Trivin F, Porquet D. Effect of hemolysis on the concentration of insulin in serum determined by RIA and IRMA. Clin Chem 1998;44:354-6.

[15] Woods AE. Laboratory histopathology: a complete reference: Churchill Livingstone; 1994.

[16] Beutler E. Improved method for the determination of blood glutathione. J Lab Clin Med 1963;61:882-8.

[17] Aebi H. Catalase in vitro. Meth Enzymol 1984;105:121-6.

[18] Kei S. Serum lipid peroxide in cerebrovascular disorders determined by a new colorimetric method. Clin Chim Acta 1978;90:37-43.

[19] Montgomery H, Dymock JA, 414. Determination of nitric oxide. Analyst $1961 ; 86: 414$ 
[20] Dai C, Krantz SB. Interferon $\gamma$ induces upregulation and activation of caspases 1, 3, and 8 to produce apoptosis in human erythroid progenitor cells. Blood 1999;93:3309-16.

[21] Ho R. Handbook of univariate and multivariate data analysis with IBM SPSS; second ed.CRC press, Taylor and Francis Group, Newyork, USA; 2013.

[22] Tuomilehto J, Borch-Johnsen K, Molarius A, Forsen T, Rastenyte D, Sarti C, et al. Incidence of cardiovascular disease in Type 1 (insulin-dependent) diabetic subjects with and without diabetic nephropathy in Finland. Diabetologia 1998;41:784-90.

[23] Yi X, Nickeleit V, James LR, Maeda N. $\alpha$-Lipoic acid protects diabetic apolipoprotein E-deficient mice from nephropathy. J Diab Complicat 2011;25:193-201.

[24] Malarkodi K, Sivaprasad R, Varalakshmi P. Effect of lipoic acid on the oxidoreductive status of red blood cells in rats subject to oxidative stress by chronic administration of adriamycin. Hum Exp Toxicol 2004;23:12935 .

[25] Jacob S, Rett K, Henriksen EJ, Häring HU. Thioctic acid-effects on insulin sensitivity and glucose-metabolism. Biofactors 1999;10:169-74.

[26] Diesel B, Kulhanek-Heinze S, Höltje M, Brandt B, Höltje H-D, Vollmar AM, et al. $\alpha$-Lipoic acid as a directly binding activator of the insulin receptor: protection from hepatocyte apoptosis. Biochem 2007;46:2146-55.

[27] Henriksen EJ. Exercise training and the antioxidant $\alpha$-lipoic acid in the treatment of insulin resistance and type 2 diabetes. Free Radical Biol Med 2006;40:3-12.

[28] El Barky AR, Hussein SA, Alm-Eldeen A-E. Saponins and their potential role in diabetes mellitus. Diab Man 2017;7:148.

[29] Mediha A, Engin G, Neslihan S. Preventive effects of LA on diabetic nephropathy in a rat model. Acta Med Medi 2014;30:1221.

[30] Morakinyo AO, Awobajo FO, Adegoke OA. Effects of alpha lipoic acid on blood lipids, renal indices, antioxidant enzymes, insulin and glucose level in streptozotocin-diabetic rats. Biol Med 2013;5:26.

[31] Kagan VE, Shvedova A, Serbinova E, Khan S, Swanson C, Powell R, et al. Dihydrolipoic acid-a universal antioxidant both in the membrane and in the aqueous phase: reduction of peroxyl, ascorbyl and chromanoxyl radicals. Biocheml pharmacol 1992;44:1637-49.

[32] Melhem MF, Craven PA, Liachenko J, DeRubertis FR. $\alpha$-Lipoic acid attenuates hyperglycemia and prevents glomerular mesangial matrix expansion in diabetes. J Am Soc Nephrol 2002;13:108-16.
[33] Brownlee M. The pathobiology of diabetic complications: a unifying mechanism. Diabetes 2005;54:1615-25.

[34] Siu B, Saha J, Smoyer WE, Sullivan KA, Brosius FC. Reduction in podocyte density as a pathologic feature in early diabetic nephropathy in rodents: prevention by lipoic acid treatment. BMC nephrol. 2006;7:6.

[35] Sadi G, Eryilmaz N, Tütüncüoğlu E, Cingir \$̧, Güray T. Changes in expression profiles of antioxidant enzymes in diabetic rat kidneys. Diabetes-Metab Res 2012;28:228-35.

[36] Kishi Y, Schmelzer JD, Yao JK, Zollman PJ, Nickander KK, Tritschler HJ, et al. Alpha-lipoic acid: effect on glucose uptake, sorbitol pathway, and energy metabolism in experimental diabetic neuropathy. Diabetes 1999;48:2045-51.

[37] JIANG Yj, GONG Dx, LIU Hb, YANG Cm, SUN Zx, KONG Cz. Ability of alphalipoic acid to reverse the diabetic cystopathy in a rat model 1 . Acta Pharmacol Sin 2008;29:713-9.

[38] Moini H, Packer L, Saris N-EL. Antioxidant and prooxidant activities of $\alpha$ lipoic acid and dihydrolipoic acid. Toxicol App Pharamacol 2002;182:8490.

[39] Cho JS, Pietras EM, Garcia NC, Ramos RI, Farzam DM, Monroe HR, et al. IL-17 is essential for host defense against cutaneous Staphylococcus aureus infection in mice. J clinl Invest 2010;120:1762-73.

[40] Packer L, Witt EH, Tritschler HJ. Alpha-lipoic acid as a biological antioxidant. Free radical Biol Med 1995;19:227-50.

[41] Rochette L, Ghibu S, Richard C, Zeller M, Cottin Y, Vergely C. Direct and indirect antioxidant properties of $\alpha$-lipoic acid and therapeutic potential. Mol Nutri food Res 2013;57:114-25.

[42] Shoukheba MY, Ibrahim WS. Caspase-3 activity as a novel biomarker in type 2 diabetes mellitus patients with chronic periodontitis. Egy Den J 2016;62:20-31.

[43] dos Santos PS, Feitosa CM, Saldanha GB, da Rocha Tomé A, Feng D, de Freitas RM. Lipoic acid inhibits caspase-dependent and-independent cell death pathways and is neuroprotective against hippocampal damage after pilocarpine-induced seizures. Pharamacol Biochem Behav 2011;97:531-6. 